\title{
Behavior of Sethoxydim Alone or in Combination with Turnip Oils on Chlorophyll Fluorescence Parameter
}

\author{
Hossein HAMMAMI ${ }^{1 *}$, Mohammad Hassan RASHED MOHASSEL ${ }^{1}$, Mehdi PARSA, \\ Mohammad BANNAYAN-AVAL ${ }^{1}$, Eskandar ZAND ${ }^{2}$ \\ ${ }^{1}$ Department of Agronomy, College of Agriculture, Ferdowsi University of Mashhad, Mashhad, Iran \\ ${ }^{2}$ Department of Weed Research, Plant Protection Research Institute, Tehran, Iran; bomamihossein@gmail.com ('corresponding author)
}

\begin{abstract}
Sethoxydim is an acetyl-coenzyme A carboxylase (ACCase) inhibitor that changed the shape of the chlorophyll fluorescence curve (kautsky curve) in wild oat (Avena ludoviciana Durieu.) in greenhouse experiment. This experiment was conducted as completely randomized factorial design with three replications at the College of Agriculture, Ferdowsi University of Mashhad, Iran, during 2012. Results of this study revealed that sethoxydim only and plus emulsifiable turnip oil changed the shape of the chlorophyll fluorescence curve (kautsky curve) 7 days after spraying. Sethoxydim plus emulsifiable turnip oil changed the shape of the kautsky curve more than for sethoxydim only. We found that in our study the $\mathrm{fv} / \mathrm{fm}$ (maximum quantum efficiency) was closely linked to the fresh and dry weight dose-response. Sethoxydim plus emulsifiable turnip oil proved more rapidly effect on fv/fm in comparison with sethoxydim only. The fresh and dry weight dose-response relationship with $\mathrm{fv} / \mathrm{fm}$ showed a similar behavior. This study revealed a good relation between fresh and dry weight according with values of $28 \mathrm{DAS}$ and fv/fm 7 DAS. In general, the findings of this study revealed that Fv/Fm is a good parameter for evaluating effect of sethoxydim little time after spraying. Also, this research showed that 4 folds more time for classical screening methods comparing to chlorophyll fluorescence method. Thereupon, classical screening methods may be replaced by chlorophyll fluorescence method in future.
\end{abstract}

Keywords: kautsky curve, sethoxydim, turnip oil, wild oat

Abbreviation: DAS=days after spraying

\section{Introduction}

Among the most harmful weeds in the world (18 species), 10 species that belongs to Poaceae family. Wild oat is the most important among these 10 species weeds in more than 20 crops in 55 countries (Salehian and Eshaghi, 2012). Also wild oat is the most important grass weed in Iranian cropping systems (Bijanzadeh et al., 2010). Among the methods of weed management, the application of herbicides is the most common method in Iran (Baghestani et al., 2008).

Sethoxydim is a selective post emergence and foliarabsorbed herbicide that belongs to aryloxy phenoxy propionate (AOPP) group that was registered for numerous broad-leaved crops including cotton, soybean, canola, alfalfa, sunflower, sugar beet, tobacco, ornamental trees, shrubs, flowers and ground cover (Senseman, 2007). It inhibits the enzyme acetyl coenzyme-A carboxylase and disrupts fatty acid biosynthesis in grasses such as wild oat (Avena fatua L. and Avena ludoviciana Durieu.), bahiagrass (Paspalum notatum), crabgrass (Digitaria sanguinalis), downybrome (Bromus tectorum), quackgrass (Elytrigia repens), annual ryegrass (Lolium multiflorum) and witchgrass (Panicum spp.) (Basf, 2000; Senseman, 2007) but dicotyledonous species are not sensitive to sethoxydim and it doesn't have effect on broadleaf herbs and crops. Non-susceptible broadleaf species have a different acetyl CoA carboxylase binding site rendering them immune to the effects of sethoxydim. Increasing the effectiveness of the post-emergence herbicides such as sethoxydim, imazamethabenz-methyl and sulfosulfuron by approved vegetable oils were reported (Izadi-Darbandi et al., 2013). So, use of vegetable oils is known as a tool for reducing herbicide usage which allows to decrease the environmental risk (Izadi-Darbandi et al., 2013).

Chlorophyll fluorescence method is non-destructive with high sensitive, fast and easy to measure, and it contains important information about the photosynthetic apparatus (Barbagallo et al., 2003), so researcher researchers would be able to quickly prescribe herbicide performance before the visual symptoms appear in plants (Riethmuller-Haage et al., 2006). Chlorophyll fluorescence can be altered by many processes that are not directly involved in photosynthesis (Crudace, 2000) so evaluation of changes to the 
chlorophyll fluorescence curve (kautsky curve) can be used for study of the effect of the herbicides with each to mode of action (Barbagallo et al., 2003). For example varic Barbagallo et al. (2003) showed change in chlorophyll fluorescence parameters in Mousear Cress (Arabidopsis thaliana) seedlings by asulam, bifenox, 2,4-D, glyphosate, diclofop-methyl, and imazapyr. Also, Avarsaji et al. (2012) reported the same with Dicamba+2, 4-D herbicides on wild mustard (Sinapis arvensis), which don't have a direct impact on photosynthesis. The advantage of this approach is represented by the possibility of using a portable instrument with rapid collection of data and advanced software enabling statistical analysis (Klem et al., 2002).

Kautsky curve has three phases based on the O, J, I, and P steps (Fig. 1). These phases indicate photochemical events related to PSII (Govindjee, 1995) and interpreted as follows: (I) (O-J) phase corresponds to a complete reduction of the primary electron acceptor QA of PSII, this phase takes place within $50 \mu \mathrm{s}$ to $2 \mathrm{~ms}$, (II) (J-I) phase corresponds to electron transfer from $\mathrm{QA}$ to $\mathrm{QB}$ the release of fluorescence quenching during the $[\mathrm{J}-\mathrm{I}]$ phase is controlled by the PSII donor side, This phase takes place within 2 to $30 \mathrm{~ms}$ and (III) (I-P) phase corresponds to the release of fluorescence quenching by the oxidized plastoquinone pool that takes place within 30-500 ms (Fig.1) (Avarseji et al., 2012; Elahifard et al., 2013; Abbaspoor et al., 2006; Abbaspoor and Streibig, 2005).

Illumination of dark-adapted leaves produces a rise in fluorescence from the ground state (Fo) at the $\mathrm{O}$ step to its maximum value $(\mathrm{Fm})$ at the $\mathrm{P}$ step within a second. Under this condition, QA is completely reduced and the value of maximum quantum efficiency $(\mathrm{Fv} / \mathrm{Fm})$ can be determined, this value in all unstressed leaves plants, independent of species, is approximately equal to 0.83 (Abbaspoor and Streibig, 2005; Appenroth et al., 2000; Strasser and Stirbet, 2001). The shape of the kautsky curve is affected by various factors, such as temperature, water stress, pathogens and herbicides (Abbaspoor and Streibig, 2005).

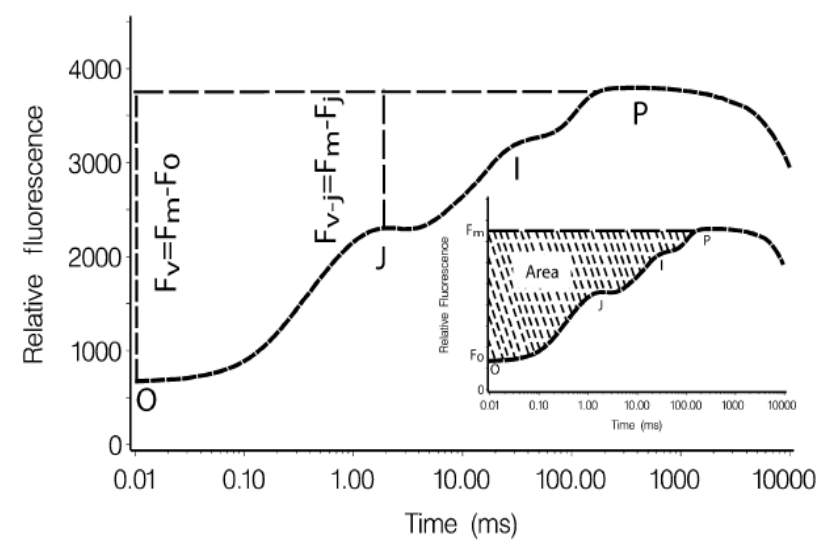

Fig. 1. Chlorophyll fluorescence curve (kautsky curve) recorded with Handy PEA instrument in a 30 min darkadapted leaf (adopted by Abbaspoor and Streibig, 2005)
$\mathrm{J}$ step $[\mathrm{Fvj}=(\mathrm{Fm}-\mathrm{Fj}) / \mathrm{Fm}]$ (Fig. 1) have been selected to be a common response parameter for an herbicide with various modes of actions (Christensen et al., 2003).

The goals of this study were to assess the effect of sethoxydim and sethoxydim plus turnip oil on the shape of the kautsky curve in wild oat and related parameters.

\section{Materials and methods}

\section{Plant growth}

About 200 gr wild oat caryopsis fruit were collected from plants in the field adjacent to the Research Greenhouse at the Ferdowsi University of Mashhad, Iran and preserved in a refrigerator $\left(\right.$ at $\left.4 \pm 1^{\circ} \mathrm{C}\right)$. To break seed dormancy before the start of experimentation, caryopsis fruits were dehulled and seeds were placed in $11 \mathrm{~cm}$ diameter Petri dishes over the surface of a single layer of Whatman no. 1 filter paper. Ten ml of $\mathrm{KNO}_{3}$ solution $(2 \mathrm{~g}$ $\mathrm{L}^{-1}$ ) were added to each Petri dish and they were placed in a refrigerator at $4-5{ }^{\circ} \mathrm{C}$ in the dark for two days and then transferred to an incubator with $20 / 10^{\circ} \mathrm{C}$ temperature in $45 / 65 \%$ relative humidity for a $16 / 8 \mathrm{~h}$ day/night for germination (Hammami et al., 2011). Five seeds were sown in potting trays $(3 \times 3 \times 5 \mathrm{~cm})$ filled with moistened peat. One week after sowing, when the seedlings had one leaf, each of them were transplanted in $2 \mathrm{~L}$ plastic pots that were filled with a mixture of sand, clay loam soil, and peat $(1: 1: 1 ; \mathrm{v} / \mathrm{v} / \mathrm{v})$. The pots were irrigated every three days with tap water. The seedlings were thinned to five per pot at the two leaf stage and $40 \mathrm{~mL}$ of a water-soluble N:P:K (20:20:20) fertilizer, at a concentration of $3 \mathrm{~g}$ of fertilizer per liter of tap water, were supplied to each pot. The greenhouse temperature varied from $24 \pm 3{ }^{\circ} \mathrm{C}$ during the day and $16 \pm 2^{\circ} \mathrm{C}$ at night.

\section{Dose-response study}

Sethoxydim (Nabo-S, 12.5\% EC, Basf, Germany) treatment consisted of six doses against wild oat $(0,45,94$, 187,281 , and $\left.375 \mathrm{~g} \mathrm{ai} \mathrm{ha}^{-1}\right)$. The experiment was arranged in a randomized complete factorial design with three replications and carried out in a greenhouse at the Faculty of Agriculture, Ferdowsi University of Mashhad, Iran in 2012. Turnip (Eruca sativa L.) oil seed was extracted via mechanical extraction method (Kemper, 2005). A nonionic emulsifier, Citogate (100\% alkyl aryl polyglycol ether prepared from Zarnegaran Pars Company, Karaj, Iran) was added to the turnip oil at $10 \%(\mathrm{v} / \mathrm{v})$, and $0.5 \%(\mathrm{v} / \mathrm{v})$ of this compound ( $90 \%$ vegetable oil $+10 \%$ emulsifier) was added to the sethoxydim solution. The experimental treatments were sethoxydim doses in six levels at 0 (control), 45, 94, 187, 281, and $375 \mathrm{~g}$ ai ha ${ }^{-1}$ with and without emulsifiable turnip oil. The spray treatment was done at the four leaf stage by using an overhead trolley sprayer (Matabi 121030 Super Agro 20 L sprayer; Agratech Services-Crop Spraying Equipment, Rossendale, UK), equipped with an 8002 flat fan nozzle tip delivering $240 \mathrm{~L} \mathrm{ha}^{-1}$ at 2 bar spray pressure. Four weeks after spraying, the control and treated plants above-ground biomass from each pot (all of the plants in each pot) were harvested and weighted (fresh weight) then oven dried at $75^{\circ} \mathrm{C}$ for $48 \mathrm{~h}$ and reweighed (dry weigh). 
114

\section{Statistical analysis}

Weight data of all the herbicide treatments were subjected to non-linear regression analyses by using a logistic dose-response model (Kudsk and Mathiassen, 2004):

$$
U=C+\frac{D-C}{1+\exp \left[b\left(\log (z)-\log \left(E D_{50}\right)\right)\right]}
$$

where, $U$ is the plant response to the herbicide treatment, $z$ is the dose, $D$ and $C$ are the upper and lower limits of the curve respectively. $E D_{50}$ denotes the required dose of herbicide to give $50 \%$ wild oat control and $b$ is proportional to the slope of the curve around the $E D_{50}$.

\section{Fluorescence measurement}

Chlorophyll fluorescence was measured using a portable chlorophyll fluorometer (Handy-PEA, Hansatech Instruments, King's Lynn, Norfolk, UK) after at 1,2,3,5 and 7 DAS which emits a light of $650 \mathrm{~nm}$ wave length with an intensity of $3000 \mu \mathrm{mol}$ photons $\mathrm{m}^{-2}$ $\mathrm{s}^{-1}$ for 10 seconds on dark-adapted leaves $(30$ minutes dark adapted by covering the leaves with a clip). Kautsky curves and their parameters, obtained by the pea plus program. The parameter analyzed in this experiment was $\mathrm{Fv} / \mathrm{Fm}=(\mathrm{Fm}-\mathrm{F} 0) / \mathrm{Fm}$ where $\mathrm{Fm}$ : maximum fluorescence and F0: ground state fluorescence (Fig. 1).

\section{Results and discussion}

\section{Dose-response study}

The results from this research revealed that when sethoxydim was combined with emulsifiable turnip oil, wild oat control was considerably increased. The $\mathrm{ED}_{10}$, $\mathrm{ED}_{50}$ and $\mathrm{ED}_{90}$ values of sethoxydim were remarkably decreased (Tab. 1). The performance of sethoxydim (Nabo-S, 12.5\% EC, Basf, Germany), in the presence of emulsifiable turnip oil, were equal to 2.285 and 2.876 fold compare with sethoxydim alone, for fresh weight and dry weight respectively (Tab. 1). The results indicated that emulsifiable turnip oil has potency in enhancing the foliage activity and reducing biomass wild oat of sethoxydim. The improvement of the tested sethoxydim plus emulsifiable turnip oil may be related to a theory which shows the solubilizing, softening or disrupting nature of cuticular waxes by the methylated seed oils (Hazen, 2000).

\section{Chlorophyll Fluorescence study}

\section{The katusky curves}

Sethoxydim affected the shape of the kautsky curves significantly at 7 DAS at all doses (Fig. 2), although the onset of these changes was observed at 2 DAS (Fig. 2). By increasing the dose of the Sethoxydim OJIP steps of the kautsky curve were eliminated; at the recommended dose ( 375 gr. ai. ha ${ }^{-1}$ ) the kautsky curves turned into approximately straight lines (Fig. 2).

The effect of sethoxydim plus emulsifiable turnip oil on the shape of the kautsky curve (Fig. 3) clearly showed that the curves were severely affected at much lower doses than by comparison with sethoxydim alone (Fig. 2) (kautsky curves changed at sethoxydim plus emulsifiable turnip oil more rapidly than at sethoxydim alone).

The findings of this study revealed the non phytotoxic effect of emulsifiable turnip oil on wild oat because when emulsifiable turnip oil was applied only, kautsky curves didn't change in compare control (Fig. 2, 3). Likewise, IzadiDarbandi et al. (2013) reported that emulsifiable turnip oil non phytotoxic effect on wild oat (Avena ludoviciana L.) With the difference that chlorophyll fluorescence method was non-destructive, high sensitive, fast and easy to measure compare the measuring fresh and dry weight (Barbagallo $e t$ al., 2003). Actually in according to findings of this study use of chlorophyll fluorescence method supplies the measuring of sethoxydim and sethoxydim plus emulsifiable turnip oil effect after 7 DAS, whereas more than 4 folds time needs for measuring of sethoxydim and sethoxydim plus emulsifiable turnip oil with use of measuring fresh and dry weight (IzadiDarbandi et al., 2013). In general, sethoxydim and sethoxydim plus emulsifiable turnip oil changed kautsky curves but changes for sethoxydim plus emulsifiable turnip oil happen more rapidly by comparison with sethoxydim only.

\section{The fluorescence parameters}

The inhibition of acetyl CoA carboxylase prevents fatty acid production, which leads to I) failure of cell membrane integrity especially in regions of active growth II) breakdown of membrane and accumulation of polyunsaturated fatty acids III) produces reactive oxygen species (ROS) with lipoxygenase activity on polyunsaturated fatty acids (Theodoulou et al., 2003; Luo et al., 2004; Senseman, 2007).

Tab. 1. The ED10, ED50 and ED90 ( $\mathrm{g}$ a.i. ha ${ }^{-1}$ ) of sethoxydim alone and in mixture with turnip oil against wild oat (Avena ludoviciana $\mathrm{L}$.)

\begin{tabular}{|c|c|c|c|}
\hline Herbicide + vegetable oil & $\mathrm{ED}_{10}\left(\mathrm{~g}\right.$ a.i. ha $\left.{ }^{-1}\right) \pm \mathrm{SE}$ & $\mathrm{ED}_{50}\left(\mathrm{~g}\right.$ a.i. ha $\left.{ }^{-1}\right) \pm \mathrm{SE}$ & $\mathrm{ED}_{90}\left(\mathrm{~g}\right.$ a.i. ha $\left.{ }^{-1}\right) \pm \mathrm{SE}$ \\
\hline \multicolumn{4}{|c|}{ Dry Weight } \\
\hline Sethoxydim alone & $32.18 \pm 2.88$ & $80.00 \pm 2.85$ & $222.16 \pm 2.16$ \\
\hline Sethoxydim + turnip & $4.86 \pm 1.12$ & $27.81 \pm 0.13$ & $139.82 \pm 1.06$ \\
\hline \multicolumn{4}{|c|}{ Fresh Weight } \\
\hline Sethoxydim alone & $47.60 \pm 1.14$ & $100.93 \pm 1.43$ & $215.83 \pm 1.56$ \\
\hline Sethoxydim + turnip & $12.01 \pm 0.38$ & $44.17 \pm 0.08$ & $88.93 \pm 0.31$ \\
\hline
\end{tabular}

The Turnip oil added at $0.5 \%(\mathrm{v} / \mathrm{v})$ that $5 \%$ of the vegetable oils were non-ionic alkyl aryl polyglycol ether emulsifier. 
Due to the production of ROS, numerous damaging reactions are initiated, collectively called oxidative stress, that causes a destruction of the electron transport chain from PSII to PSI (Sofo et al. 2004). This destruction has an influence on chlorophyll fluorescence, probably allowing the detection of herbicide efficacy by measuring maximum quantum efficiency of PSII. So, chlorophyll fluorescence can be used as tool for detection of herbicide performance with other mode of action such as acetyl coenzyme-A carboxylase inhibitor (Abbaspoor and streibig, 2005), phenoxy (Avarseji et al., 2012) and glyphosate (Christensen et al., 2003).

Changes in the shape of the kautsky curves are described
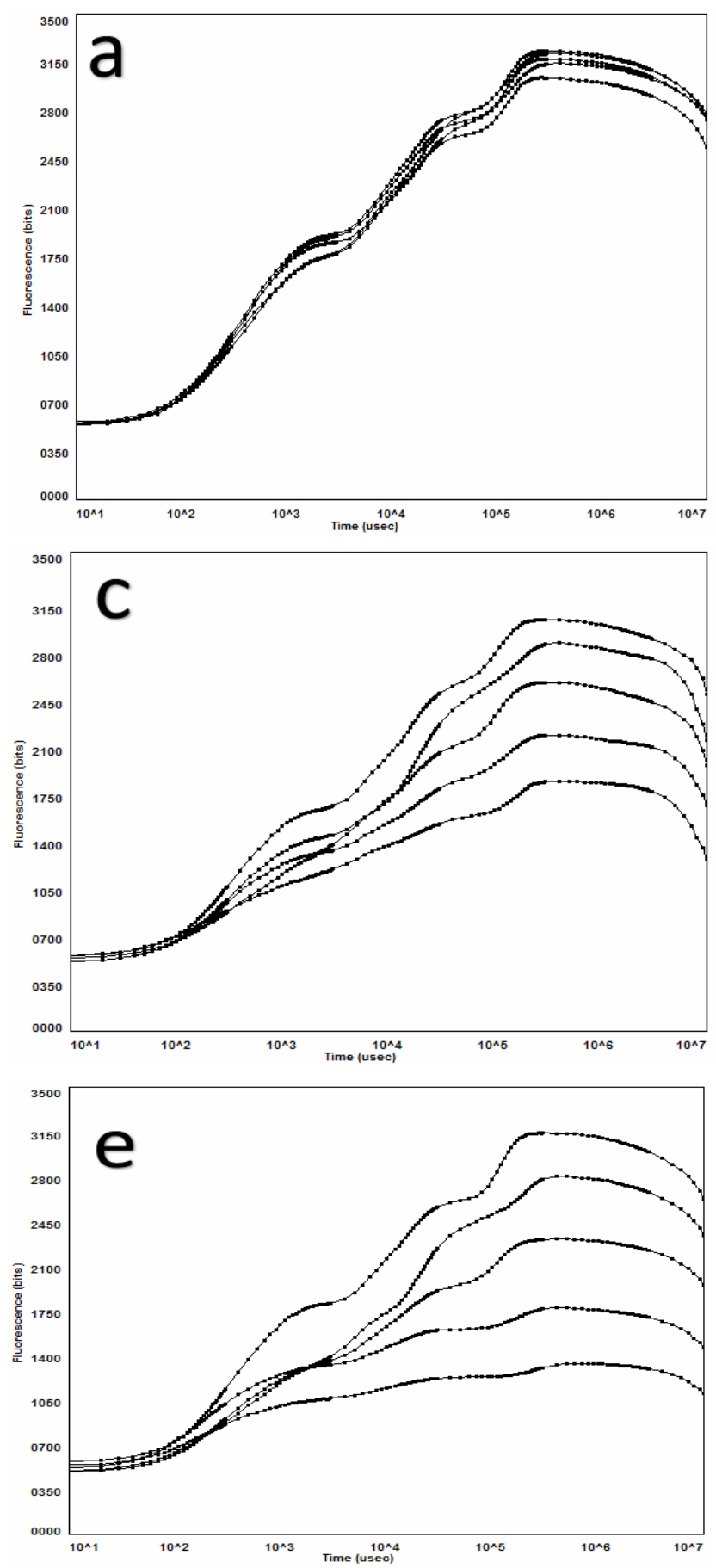

in Figs. 2, 3. Important fluorescence parameters $\mathrm{Fv} / \mathrm{Fm}$ was plotted at the range of doses of sethoxydim at 1, 2, 3, 5 and 7 DAS and relationship between $\mathrm{Fv} / \mathrm{Fm}$ with fresh and dry weight is shown in Figs. 4, 5, 6. The Fv/Fm was greatly decreased as the dose was increased in sethoxydim plus emulsifiable turnip oil in compare with sethoxydim only (Figs. 2, 3). The value of the Fv/Fm parameter is about 0.83 in healthy leaves, regardless of plant species (Abbaspoor and Streibig, 2007; Stribet and Govindjee, 2011) but it is reduced under stress conditions such as high temperature, salinity, drought and herbicides.

In this experiment, $\mathrm{Fv} / \mathrm{Fm}$-values of the control plants
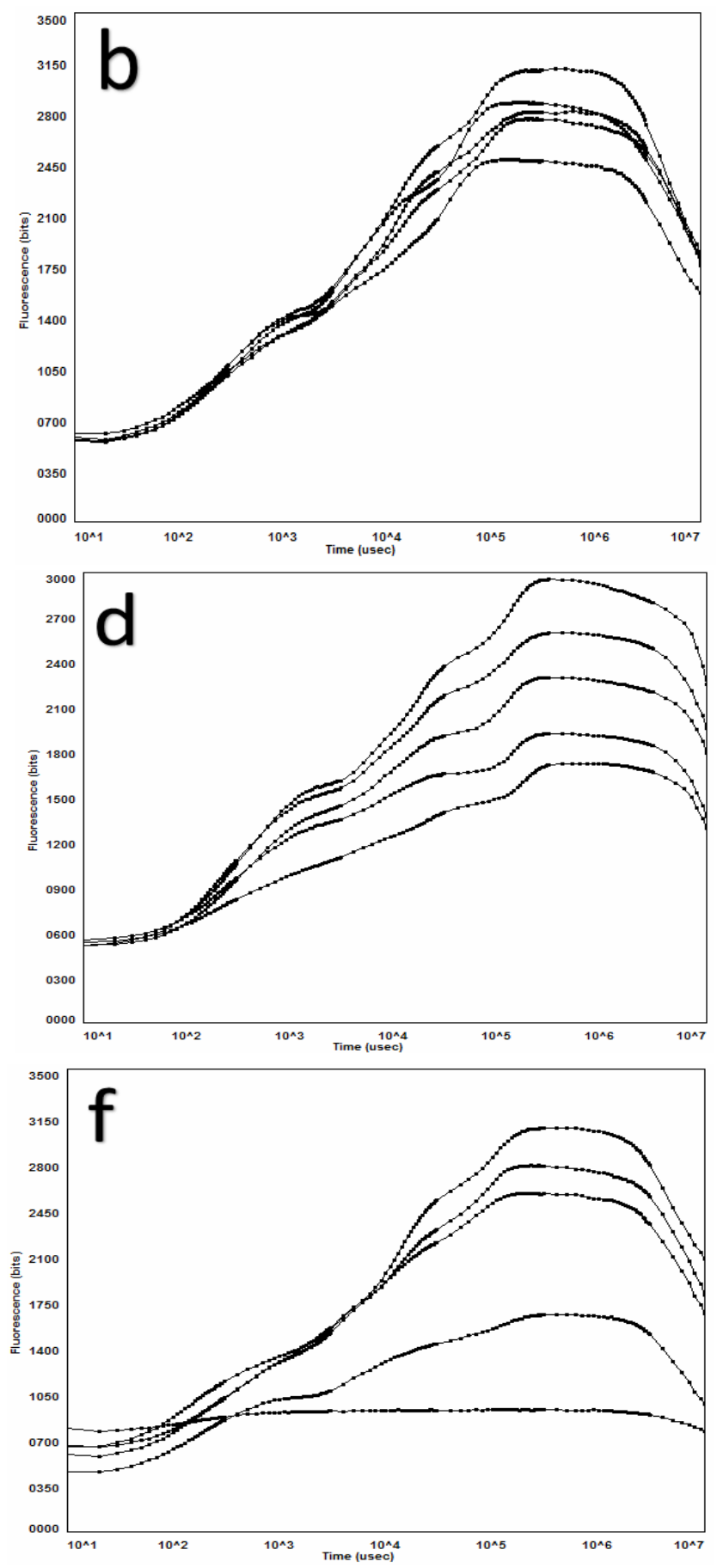

Fig. 2. Effect of sethoxydim only on the shape of the katusky curve in wild oat at 1, 2, 3, 5 and 7 days after treatment: a; 0, b; 45, c; 94, d; 187, e; 281 and f; 375 gr a.i. /ha 
116
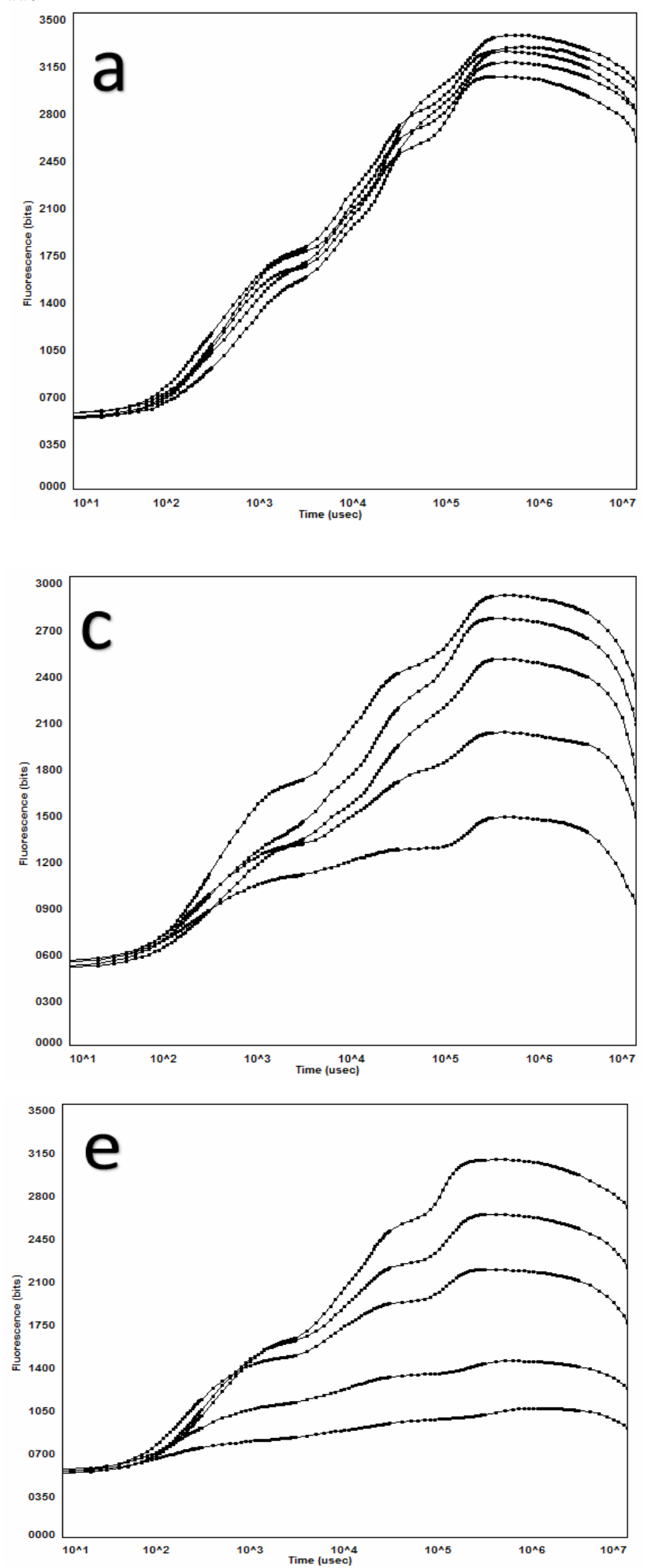
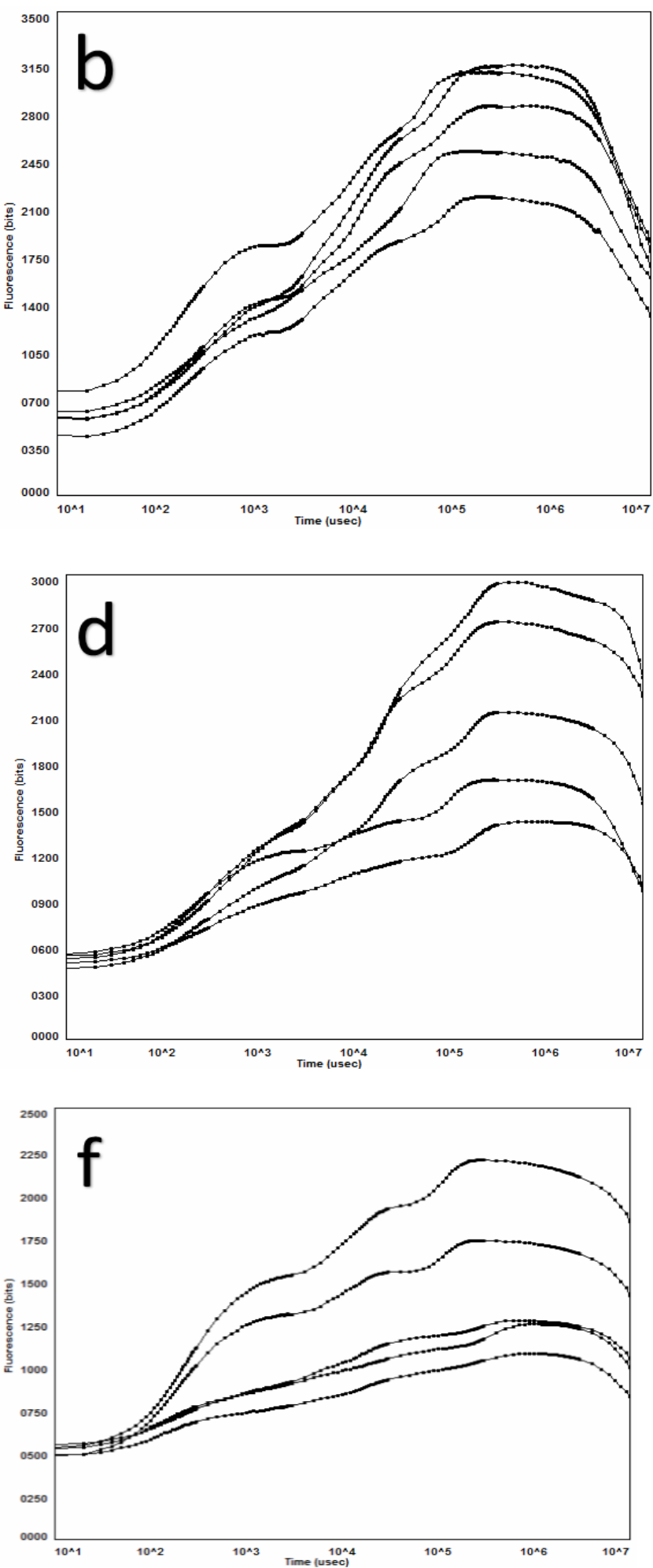

Fig. 3. Effect of sethoxydim plus turnip oil on the shape of the katusky curve in wild oat at 1,2, 3, 5 and 7 days after treatment: a; $0, \mathrm{~b} ; 45, \mathrm{c} ; 94, \mathrm{~d} ; 187, \mathrm{e} ; 281$ and $\mathrm{f} ; 375$ gr a.i. /ha

were between 0.835 and 0.846 at all times of measurement. By increasing the dose of the sethoxydim $\mathrm{Fv} / \mathrm{Fm}$-values were decreased whereas after $7 \mathrm{DAS} \mathrm{Fv} / \mathrm{Fm}$ of 0.846 (control) get to 0.479 and 0.547 at the recommended dose (375 g. ai. ha ${ }^{-1}$ ) with and without emulsifiable turnip oil respectively. Rate of decrease $\mathrm{Fv} / \mathrm{Fm}$-values for applied emulsifiable turnip oil as adjuvant was higher compared sethoxydim alone. Fv/Fm decreased with past time as 7 DAS at least this parameter was observed (Fig. 4). 

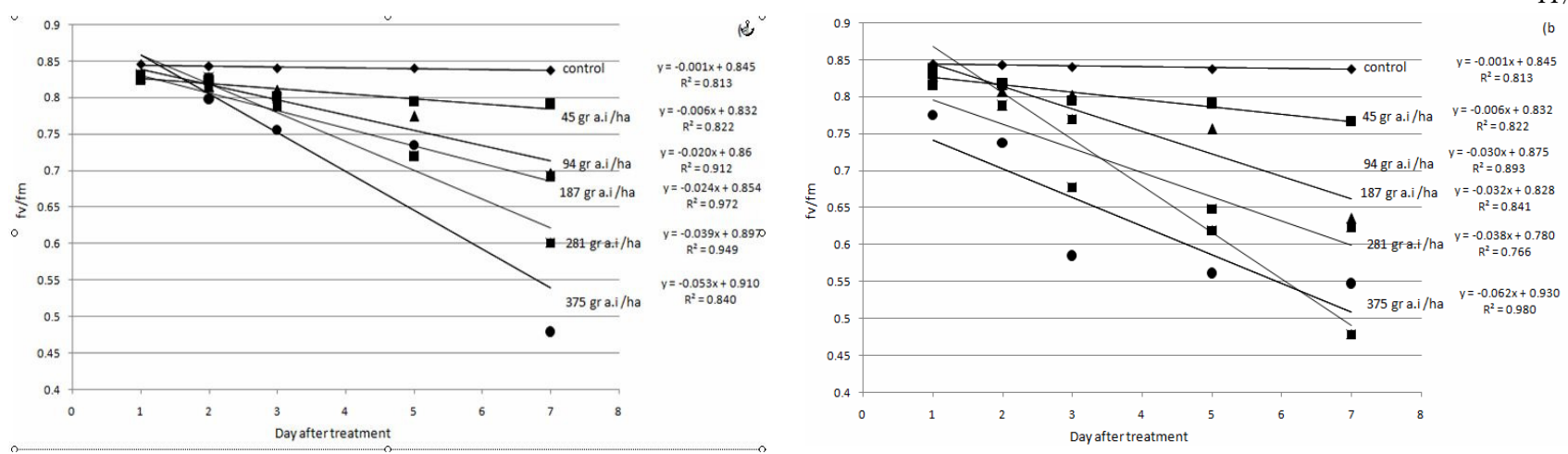

Fig. 4. Relationship between Fv/Fm parameter and days after treatment: a; sethoxydim only and b; sethoxydim plus turnip oil
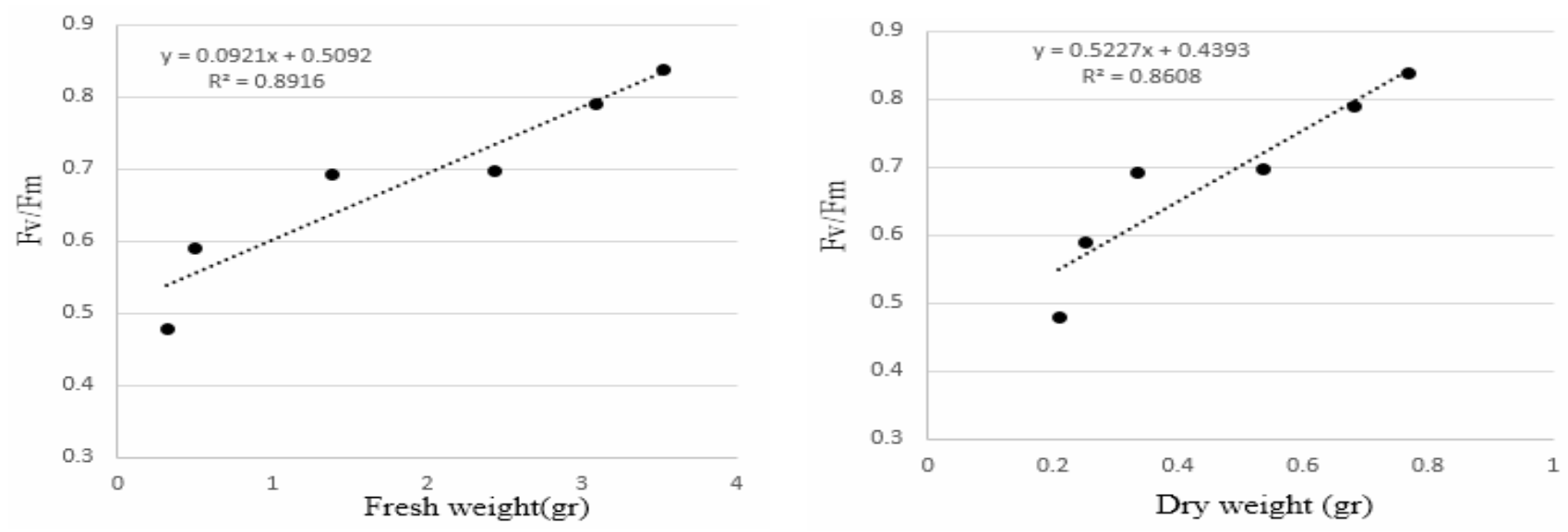

Fig. 5. Relationship between Fv/Fm parameter and fresh and dry weight at 7 days after spraying on sethoxydim only
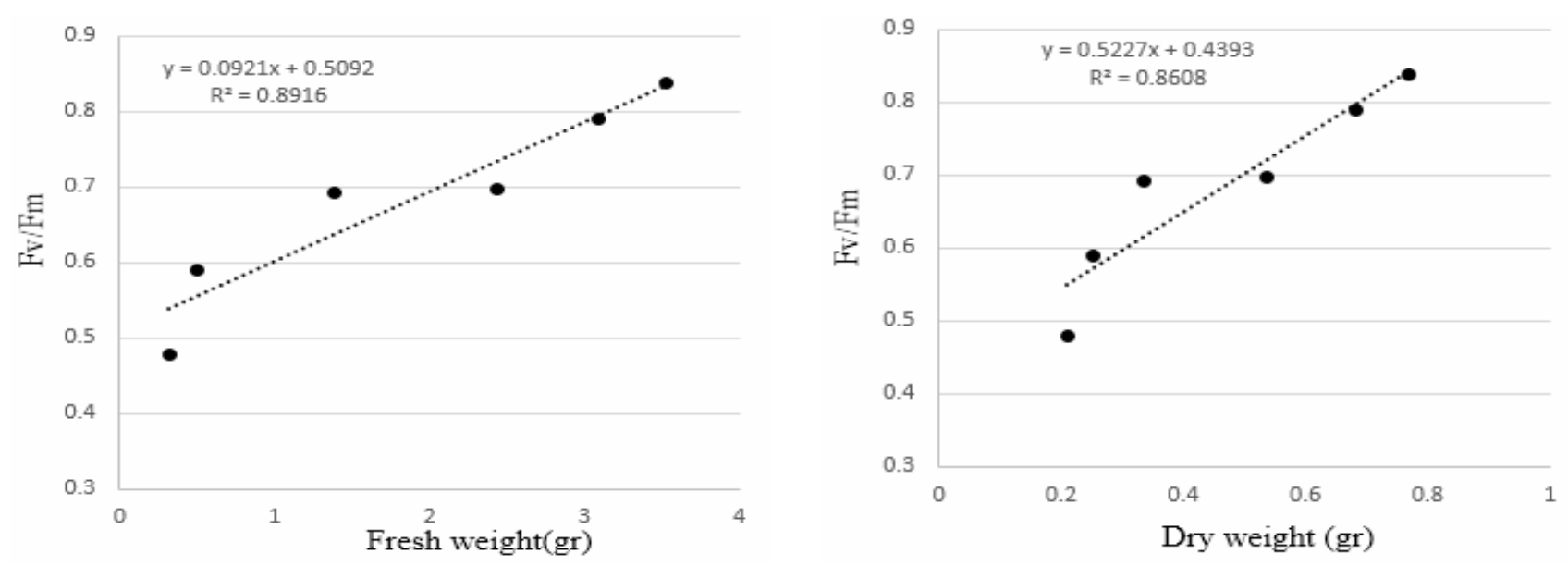

Fig. 6. Relationship between Fv/Fm parameter and fresh and dry weight at 7 days after spraying on sethoxydim plus emulsifiable turnip oil

The relationship between fresh and dry weight with fluorescence parameter

Figs. 5, 6 illustrate the relationships between fresh and dry weight (taken at 28 DAS) with fluorescence parameter (Fv/Fm) taken at 7 DAS for sethoxydim and sethoxydim plus turnip oil, respectively. The slope of the curves is steeper for sethoxydim plus turnip oil compared sethoxydim alone. A linear relationship between $\mathrm{Fv} / \mathrm{Fm}$ with fresh and dry weight is evident. Other researchers, also, used relationship between fluorescence parameter and dry weight

for bentazone (Christensen et al., 2003), metamitron and terbuthylazine (Abbaspoor et al., 2006), clodinafop (Abbaspoor and Streibig, 2005), desmedipham and phenmedipham (Abbaspoor and Streibig, 2007) and fresh weight (Elahifaru et al., 2013) in their experiments.

\section{Conclusions}

Based on available information and experimental evidence classical screening methods can be replaced by Chlorophyll Fluorescence studies. Because Chlorophyll Fluorescence method is a non-destructive, high sensitive 
118

and fast compared to classical screening methods. The findings of this study revealed that $\mathrm{Fv} / \mathrm{Fm}$ is a good parameter for evaluating the effect of herbicide shortly after spraying. Also this research showed that 4 folds more time for classical screening methods compared to chlorophyll fluorescence method. So the use of chlorophyll fluorescence method may be increased in herbicide bioassay studies in the future. Based on conducted studies by various researchers due to the production oxidative stress, numerous damaging reactions are initiated that cause an interruption of the electron transport chain from PSII to PSI, so chlorophyll fluorescence method can be used for herbicides with various mode of action. Finally, the linkage between fresh and dry weight and the fluorescence parameters may be used to shorten the screening experiments times for ACCase inhibitors.

\section{References}

Abbaspoor M, Streibig JC (2005). Clodinafop changes the chlorophyll fluorescence induction curve. Weed Sci 53:1-9.

Abbaspoor M, Teicher HB, Streibig JC (2006). The effect of root-obsorbed PSII inhibitors on Kautsky curves parameters in sugar beet. Weed Res 46:226-235.

Abbaspoor M, Streibig JC (2007). Monitoring the efficacy and metabolism of phenylcarbamates in sugar beet and black nightshade by chlorophyll fluorescence parameters. Pest Manag Sci 63:576-585.

Appenroth KJ, Stockel J, Srivastava A, Strasser RJ (2000). Multiple effects of chromate on the photosynthesis apparatus of Spirodela polyrhiza as probed by OJIP chlorophyll A fluorescence measurements. Environ Pollut 115:49-64.

Avarseji Z, RashedMohassel MH, Nezami A, Abbaspoor M, NassiriMahallati M (2012). Dicamba + 2, 4-D affects the shape of the Kautsky curves in wild mustard (Sinapis arvensis). Plant Knowl J 1:41-45.

Baghestani MA, Zand E, Soufizade S, Beheshtian M, Haghighi A, Barjasteh A, Birgani DG, Deihimfard R (2008). Study on the efficacy of weed control in wheat (Triticum aestivum L.) with tank mixtures of grass herbicides with broadleaved herbicides. Crop Prot 27:104-111.

Barbagallo RP, Oxborough K, Pallett KE, Baker NR (2003). Rapid, non-invasive screening for perturbations of metabolism and plant growth using chlorophyll fluorescence imaging. Plant Physiol 132:485-493.

BASF (2000). Poast Herbicide Label. C \& P Press. p 1-18.

Bijanzadeh E, Naderi R, Behpoori A (2010). Interrelationships between oilseed rape yield and weeds population under herbicides application. Aust J Crop Sci 4(3):155-162.

Christensen MG, Teicher HB, Streibig JC (2003). Linking fluorescence induction curve and biomass in herbicide screening. Pest Manag Sci 59:1303-1310.

Crudace AJ (2000). The investigation of the in vivo behavior of a maize herbicide-Isoxaflutole. PhD thesis. University of Essex. Colchester, United Kingdom.

Elahifard E, Ghanbari A, RashedMohassel MH, Zand E,
MirshamsiKakhki A, Abbaspoor M (2013). Measuring chlorophyll fluorescence parameters for rapid detection of ametryn resistant junglerice (Echinochloa colona (L.) Link.). Plant Knowl J 2:76-82.

Govindjee (1995). Sixty-three Years since Kautsky: Chlorophyll a Fluorescence. Aust J Plant Physiol 22:131160.

Hammami H, RashedMohassel MH, Aliverdi A (2011). Surfactant and rainfall influenced clodinafop-propargyl efficacy to control wild oat (Avena ludoviciana Durieu.). Aust J Crop Sci 5:39-43.

Hazen JL (2000). Adjuvants: terminology, classification, and chemistry. Weed Technol 14:773-784.

Izadi-Darbandi E, Aliverdi A, Hammami H (2013). Behavior of vegetable oils in relation to their influence on herbicides' effectiveness. Indus Crops and Prod 44:712717.

Klem K, Spundova M, Hrabalova H, Naus J, Vanova M, Masojidek J, Tomek P (2002). Comparison of chlorophyll fluorescence and whole-plant bioassays of isoproturon. Weed Res 42:335-341.

Kudsk P, Mathiassen SK (2004). Joint action of amino acid biosynthesis inhibiting herbicides. Weed Res 44:313-322.

Luo XY, Sunohara Y, Matsumoto H (2004). Fluazifop-butyl causes membrane peroxidation in the herbicide-susceptible broad leaf weed bristly starbur (Acanthospermum hispidum). Pestic Biochem Physiol 78:93-102.

Riethmuller-Haage I, Bastiaans L, Kropff MJ, Harbinson J, Kempenaar C (2006). Can photosynthesis-related parameters be used to establish the activity of acetolactate synthase-inhibiting herbicides on weeds? Weed Sci 54:974-982.

Rodriguez R, Strasser R (2002). The laboratory of bioenergetics. University of Geneva, Switzerland. http://www. unige. ch/sciences/biologie/bioen/main 1 . html.

Salehian H, Eshaghi O (2012). Growth analysis some weed species. Int J Agri Crop Sci 4:730-734.

Senseman SA (2007). Herbicide Handbook. Ninth Edition. Weed Science Society of America 458 p.

Shahidi F (2005). Bailey's Industrial Oil and Fat Products, Sixth Edition, Vol. 5, Edible Oil and Fat Products: Oil Extraction. John Wiley \& Sons, Inc. pp. 57-97.

Sofo A, Dichio B, Xiloyannis C, Masia A (2004) Effects of different irradiance levels on some antioxidant enzymes and on malondialdehyde content during rewatering in olive tree. Plant Sci 166:293-302.

Strasser RJ, Stirbet AD (2001). Estimation of the energetic connectivity of PS II centers in plants using the fluorescence rise O-J-I- P; fitting of experimental data to three different PS II models. Math and Comput Sim 56:451-461.

Theodoulou FL, Clark IM, He XL, Pallett KE, Cole DJ, Hallahan DL (2003). Co-induction of glutathione-Stransferases and multidrug resistance associated protein by xenobiotics in wheat. Pest Manag Sci 59:202-214. 